\title{
The effect of thermal, flammability, and mechanical properties of wood plastic composites made from recycled food-packaging $L D P E$ and eco-friendly phytic acid
}

\author{
Yeng-Fong Shih, Ying-Hsiao Chen*, Shi-Yun Lai, Yi-Xuan Chen, \\ Shih-Chu Wang, Shi-Pei Zhang \\ Department of Applied Chemistry, Chaoyang University of Technology, Taichung, \\ Taiwan
}

\begin{abstract}
Within this work, a novel eco-friendly flame-retardant system for wood plastic composites (WPCs) was developed based on the phytic acid modified wood flour (WF) and the silane-coupling agents treated diatomite, were incorporated into low density polyethylene (LDPE) by a melt-blending process. Via impregnation process, neutralized phytic acid $(\mathrm{PA}(\mathrm{N}))$ was absorbed into the wood porous structure to obtain phytic acid modified wood flour (WF-PA(N)), which was expected to improve the retardancy and thermal stability of the WPC composites without deterioration of their mechanical properties. Moreover, polyethylene grafted maleic anhydride (MAPE) could render the phytic acid modified woods to be well dispersion in LDPE matrix, and consequently increasing the thermal resistance properties of the composites with increasing the content of the phytic acid modified woods. The TGA analysis revealed that the char yield of the LDPE/WF-PA(N) composites (22 29\%) were higher than that of LDPE/WF (14\%), indicating improved thermal stability by the addition of WF-PA(N). The heat distortion temperature (HDT) of the LDPE/WF-PA(N) composites exhibited upward with increasing WF-PA(N) contents. Among the LDPE/WF-PA(N) composites, the one containing $45 \%$ of WF-PA(N) exhibits the best tensile and impact strength. In addition, the burning rate analysis demonstrated that LDPE composites containing WF-PA(N) has short burning rates presumably ascribed to the formation of char layer from phosphoruscontaining additives WF-PA(N). This is consistent with the results of TGA analysis.
\end{abstract}

Revised: October 11, 2021

Accepted: October 13, 2021

Corresponding Author:

Ying-Hsiao Chen

t5200825@cyut.edu.tw

Copyright: The Author(s). This is an open access article distributed under the terms of the Creative Commons Attribution License (CC BY 4.0), which permits unrestricted distribution provided the original author and source are cited.

\section{Publisher:}

Chaoyang University of

Technology

ISSN: $1727-2394$ (Print)

ISSN: 1727-7841 (Online)

\section{INTRODUCTION}

LDPE is one of the most useful commodity polymers in our daily life, due to the reasonable price, excellent processability, electrical insulating properties, good chemical properties (Guiot et al., 1999). The relevant applications include electrical appliances, wires and cables, plastic bags for computer components and so on. In the above applications, the largest practical applications for LDPE can be attributed to the packaging market significantly demands. According to the report from the Mordor Intelligence Private Limited, LDPE accounts for $55 \%$ of the global film market used in packaging of food and non-food items (Mordor Intelligence Pvt Ltd. 2020). Therefore, it boosts the growth of LDPE market and the wasted LDPE-based packing film products. Nowadays, under the requirement of the circular economy, how to effectively recycle and reuse the LDPE-based packaging films has become a very urgent research direction (Geueke et al., 2018).

Also, owing to the highly aliphatic hydrocarbon structure, LDPEs are among the most combustible materials with high heat of combustion, high heat release, and less or no 
residual ash (Zevenhoven et al., 1997; Tirri et al., 2016). To overcome these shortcomings, a wide range of technologies has been proposed for preparing flame retardant, including halogenated and non-halogenated based flame retardants (FRs) (Wang et al., 2017; Kim, 2003; Lu and Wilkie, 2010; Wang et al., 2019). While the halogen-based flame retardant has excellent flame-retardant effect, however, the halogenbased flame retardant will cause a lot of smoke and toxic gases after combustion. From the environmental and health perspective, hence, there is an urgent need to develop nonhalogenated based materials, also called as eco-friendly based materials comprising of bio-based sources and renewable resources strategies, to enhances the flame retardancy of LDPE. Up to present, the eco-friendly based flame retardant materials such as inorganic hydroxides, phosphorus, borate, silicon, and nitrogen etc. are introduced to polyethylene matrixes during manufacture processing, and the effect of flame retardant ability and mechanical properties are also studied (Prasad and Pillai, 2000; Shih et al., 2020; Ibibikcan and Kaynak, 2014; Kausar et al., 2016; Lewin and Weil, 2001; Arslan and Dilsiz, 2020) For instance, Prasad and Pillai (2000) investigated the phosphorus-containing pre-polymer could be added into the LDPE system to enhance the thermal stability and to increase the limiting oxygen index (LOI) values. In Shih et al. (2020) studied, the diatomite, the main component was silica $\left(\mathrm{SiO}_{2}\right)$, was incorporated into the HDPE/wood plastic composites (WPC) via surface modification method. They found that the addition of the silane-modified waste diatomite could reduce the usage of the flame retardant such as ammonium polyphosphate (APP) and expandable graphite (EG), and increase the mechanical properties. Ibibikcan et al. (2014) investigated the effect of the boron materials was melted into the polyethylene-based cable insulation materials to replace partial contents of metal hydroxide flame retardants (aluminium hydroxide). They found that the certain amount boron compounds could lead certain levels of enhancement in limiting oxygen index, UL94 vertical burning and mass loss in cone calorimeter analyses.

Nowadays, phosphorus-containing compounds are considered as a halogen-free flame-retardant resource because it is capable of forming stable carbonized layer that can protect the internal matrix from external heat and oxygen to improve the flame retardancy (Hörold, 1999). Especially, phytic acid (PA), which is generally founded in agricultural by-products such as rice bran and plant germ (Saad et al., 2011), has received increasing attention due to the advantages of non-toxic, easily available, biocompatible and eco-friendly (Gao et al., 2019). In the present work, a novel flame-retardant additive (WF-PA) containing phytic acid and wood flour was prepared via conventional impregnation process. This eco-friendly flame-retardant nanocomposite is applied as a major component into LDPE. The thermal stability, flame retardancy, and mechanical properties of LDPE composites were discussed in detail.

\section{EXPERIMENTAL SECTION}

\subsection{Materials}

Sodium hydroxide, and phytic acid were supplied by Sigma-Aldrich and used without further purification. Wood flour was provided by Tsung Chang Machinery Co., Ltd. Low-density polyethylene (LDPE) was supplied by Lien Tai Paper Co. Ltd., and polyethylene grafted with maleic anhydride (MAPE) was provided by Dupont. Diatomites were sourced from the Wurih Brewery, Taiwan Tobacco and Liquor Corporation, Taichung, Taiwan. The silane-coupling agents treated diatomite (SDE) were prepared according to methods previously developed in this laboratory (Shih et al., 2020).

\subsection{Preparation of Phytic Acid Modified Wood (WF- $\mathrm{PA}(\mathrm{H}))$}

Phytic acid and deionized water were charged into the 3neck round flask, and the wood flour was poured into the above mixture with vigorous stirring for an additional 3 hours at room temperature. After that, the products were then filtered and washed several times with distilled water until $\mathrm{pH}=7$ was reached. Finally, the phytic acid modified wood product (WF-PA(H)) was dried in a forced air oven at $60^{\circ} \mathrm{C}$ until a constant weight was achieved.

\subsection{Preparation of Phytic Acid Modified Wood (WF- $\mathrm{PA}(\mathrm{N}))$}

Phytic acid and deionized water were charged into the 3neck round flask, and then sodium hydroxide was slowly added to the flask until $\mathrm{pH}=7$ was reached. Wood flour was poured into the above mixture with vigorous stirring for an additional 3 hours at room temperature. After that, the products were then filtered and washed three times with distilled water. Finally, the phytic acid modified wood product (WF-PA(N)) was dried in a forced air oven at $60^{\circ} \mathrm{C}$ until a constant weight was achieved.

\subsection{Preparation of the LDPE/WF-PA(N) Composites}

As shown in Fig. 1, the preparation process of the LDPE/WF-PA(N) composites was as follows: the LDPE, MAPE, WF-PA were first dried to a constant weight. The LDPE and MAPE pellets were then pre-melted at $130^{\circ} \mathrm{C}$ in a counter-rotating internal mixer (Brabender PL2000, Duisburg, Germany) with a rotation speed of $50 \mathrm{rpm}$, followed by the addition of silane coupling agent treated diatomite (SDE) and WF-PA. The mixing chamber (volume: $50 \mathrm{~cm}^{3}$ ) was filled with $50 \mathrm{~g}$ total mass, which corresponded approximately to a filling ratio of $80 \%$. After being well blended for 3 minutes, the composite was granulated. For the purpose of characterization, the test samples of the LDPE composite were prepared by compression molding at $130^{\circ} \mathrm{C}$ for $5 \mathrm{~min}$ (under $4.90 \mathrm{MPa}$ ), for $2 \mathrm{~min}$ (under 7.35MPa), for $1 \mathrm{~min}$ (under 9.8 $\mathrm{MPa}$ ), in sequence. The formulation ( $\mathrm{wt} \%$ ) of sample is shown as Table 1 . 


\section{International Journal of Applied Science and Engineering}

Shih et al., International Journal of Applied Science and Engineering, 18(6), 2021266

Table 1. Formulation of the LDPE/WF-PA(N) composites

\begin{tabular}{cccccc}
\hline Sample & LDPE $(\%)$ & WF-PA $(\%)$ & WF (\%) & SDE (\%) & MAPE (\%) \\
\hline 50L35WF & 50 & - & 35 & 8 & 7 \\
50L35WF-PA(H) & 50 & 35 & - & 8 & 7 \\
50L35WF-PA(N) & 50 & 35 & - & 8 & 7 \\
45L40WF-PA(N) & 45 & 40 & - & 8 & 7 \\
40L45WF-PA(N) & 40 & 45 & - & 8 & 7 \\
30L55WF-PA(N) & 30 & 55 & - & 8 & 7 \\
\hline
\end{tabular}

Abbreviations: LDPE, low-density polyethylene; MAPE, polyethylene grafted with maleic anhydride; SDE, silane modified diatomite (Shih et al., 2020); WF, wood flour; WF-PA(H), phytic acid modified wood flour neutralized with distilled water; WF-PA(N), phytic acid modified wood neutralized with sodium hydroxide.

\subsection{Characterization}

Thermogravimetric analysis (TGA)

The thermal behavior was determined by TGA(TGA Q50, TA Instruments, Inc., Delaware, USA). Initially, all the samples were placed in an oven at $70^{\circ} \mathrm{C}$ to remove water traces and then scanned from 50 to $600^{\circ} \mathrm{C}$ at a heating rate of $10^{\circ} \mathrm{C} / \mathrm{min}$ in the presence of nitrogen flow.

\section{Mechanical test}

Before mechanical testing, the samples were conditioned at $65 \%$ relative humidity and $23^{\circ} \mathrm{C}$ until equilibrium moisture content was achieved. The tensile test was carried out according to the ASTM D368 test specification. The test piece was made into a dumbbell-shaped test piece having a size of $186 \mathrm{~mm} \times 19 \mathrm{~mm} \times 3 \mathrm{~mm}$, and tested with a load cell of $20 \mathrm{kN}$ at a strain rate of $50 \mathrm{~mm} / \mathrm{min}$ at room temperature by an Instron universal tester (HT-9102, Hung Ta
Instrument Co., Ltd., Taichung, Taiwan). The impact strength was analyzed according to the standard test methods for determining the Izod pendulum impact resistance of plastics (ASTM D256) using an impact resistance testing machine, Model GT-70045-MDL (Gotech Testing Machines Co., Taiwan.). Five specimens of each material were used for testing and the average values were calculated.

Heat distortion temperature test

The heat distortion temperature of the samples was determined by using High-speed rail, HV-5000A-C6. A 130 $\mathrm{mm} \times 13 \mathrm{~mm} \times 3.2 \mathrm{~mm}$ test piece was prepared in accordance with ASTM D648 test specification, and subjected to a heat distortion test under a pressure of 66 psi. The heating rate was $2^{\circ} \mathrm{C} / \mathrm{min}$. When the deformation amount of the test piece reached $1 \mathrm{~mm}$, the test was completed and the temperature was recorded.

UL-94 horizontal burning (HB) test

The UL-94 horizontal burning (HB) test was carried out according to the plastic flammability standard UL-94 issued by Underwriters Laboratories. The material thickness is less than $3 \mathrm{~mm}$, and the burning speed between $25 \mathrm{~mm}$ and 100 $\mathrm{mm}$ is calculated.

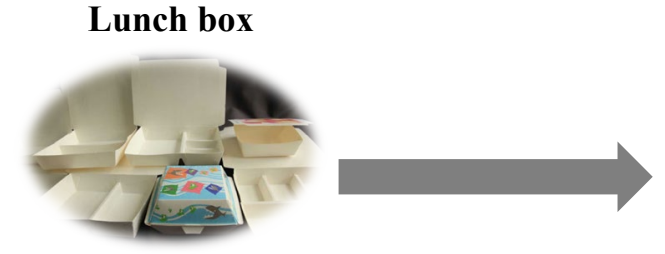

Phytic acid 50\%



Rice bran
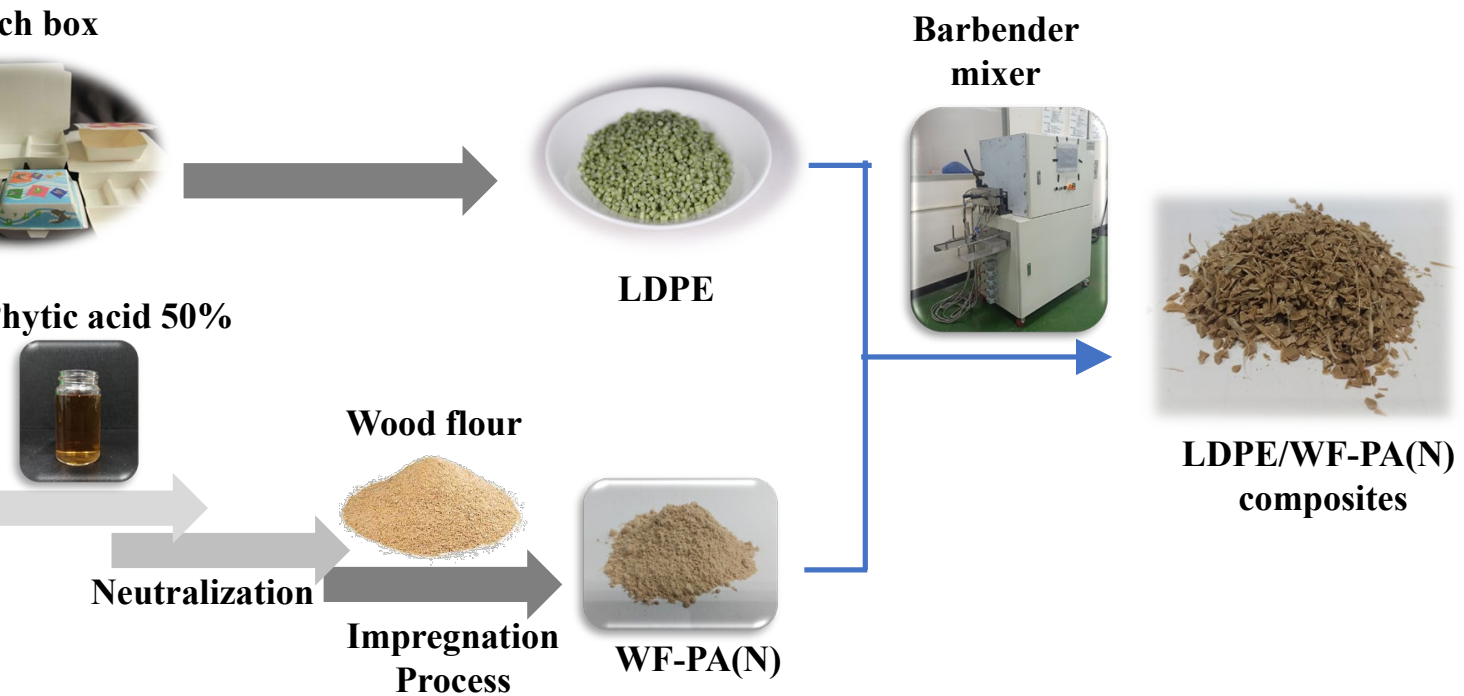

Fig. 1. The preparation process of the LDPE/WF-PA(N) composites 


\section{International Journal of Applied Science and Engineering}

Shih et al., International Journal of Applied Science and Engineering, 18(6), 2021266

\section{RESULTS AND DISCUSSION}

\section{Thermal analysis}

The thermal stability of the LDPE/WF and LDPE/WF-PA composites had been investigated in Fig. 2 and the representative parameters were presented in Table 2. First, the influence of modification process of phytic acid with wood flour was investigated and the results of TG and DTG curves are shown in Fig. 2(a) and 2(b). As can be seen, the char yield of 50L35WF was $14.67 \%$ lower than that of 50L35WF-PA(H) and 50L35WF-PA(N) were 19.36 and 22.54 , respectively. Though the 50L35WF-PA(H) and 50L35WF-PA(N) exhibited the similar thermal decomposition phenomena but the char yield of 50L35WF$\mathrm{PA}(\mathrm{N})$ was higher than that of 50L35WF-PA(H). Moreover, it could be observed the surface of 50L35WF-PA(H) composite showed partial expansion holes, while the 50L35WF-PA(N) exhibited a smoothly surface (as shown in Fig.2(a)). The expansion holes always had a negative impact on mechanical and flame retardant properties (Chan-Hom et al., 2017), therefore, we adopted WF-PA(N) as a suitable material for further research.

Furthermore, the temperature at 5\% weight loss $\left(\mathrm{T}_{5 \mathrm{wt} \%}\right)$ of neat LDPE was $418.25^{\circ} \mathrm{C}$, and exhibited one-step weight- loss process with maximum weight loss temperature $\left(\mathrm{T}_{\max }\right)$ was $477.18^{\circ} \mathrm{C}$ in nitrogen atmosphere. The LDPE/WF and LDPE/WF-PA(N) composites exhibited a similar threestage thermal weight-loss process. On analysis of the curve, it was observed that the three characteristic peaks at around $280 \sim 308^{\circ} \mathrm{C}, 315 \sim 355^{\circ} \mathrm{C}$ and $470 \sim 480^{\circ} \mathrm{C}$ could be ascribed to the decomposition of hemicellulose, cellulose and lignin, respectively (Kim et al., 2006; Brebu and Vasile, 2010; Poletto et al., 2012; Yang et al., 2005). From the DTG curves, $\mathrm{T}_{\mathrm{d} 1}$ and $\mathrm{T}_{\mathrm{d} 2}$ of LDPE/WF-PA(N) composites decreased to some extent compared to that of LDPE/WF, presumably due to the introduction of large amount of natural organic structures (PA) in the LDPE matrix. Therefore, the incorporation of the WF-PA(N) changed the thermal degradation behavior of LDPE/WF-PA(N) composites to have lower thermal decomposition temperature comparison with LDPE/WF. The WF-PA(N) decomposed first at lower temperature and formed a layer of char to protect the inner material to be decomposed. Meanwhile, it was noted that the char yield of LDPE/WF-PA(N) composites was higher than that of LDPE/WF, indicating the combination of PA(N) containing phosphorus can endow LDPE/WF composites to achieve better thermal stability.
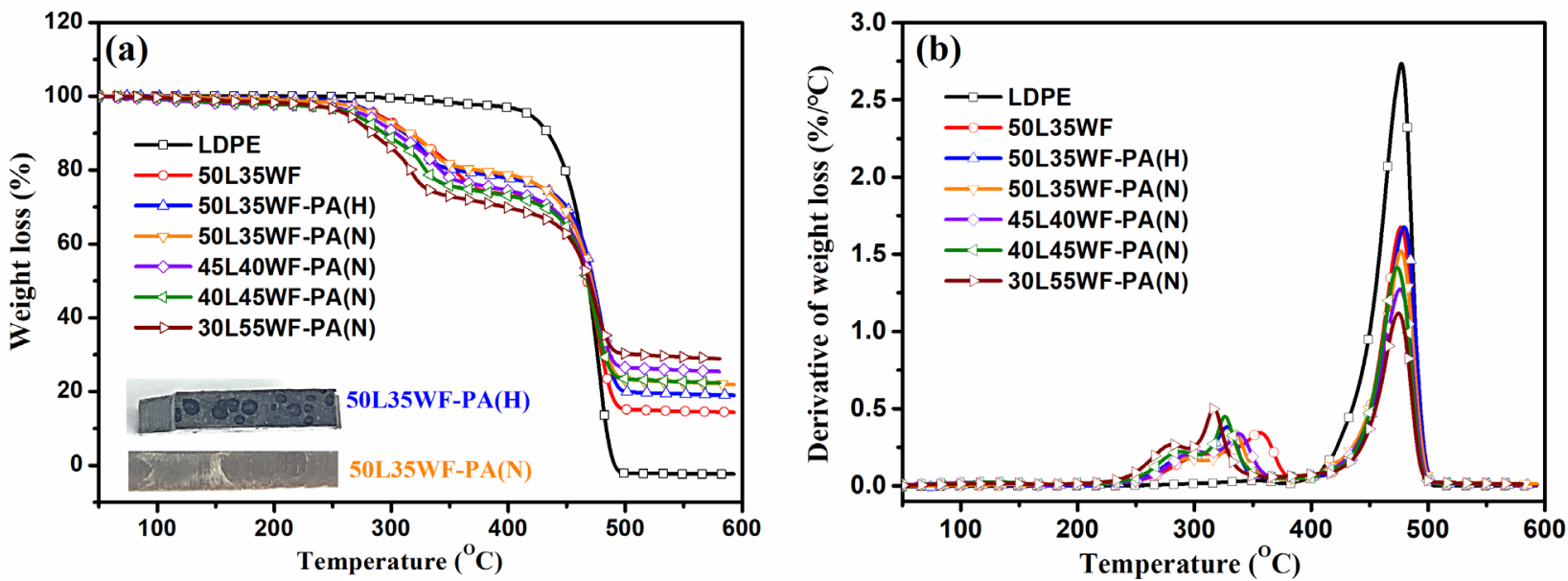

Fig. 2 (a) TGA and (b) DTG curves of the neat LDPE and LDPE/WF-PA composites at a heating rate of $10^{\circ} \mathrm{C} \mathrm{min}{ }^{-1}$ under $\mathrm{N}_{2}$

Table 2. TG and DTG data of LDPE samples under $\mathrm{N}_{2}$ atmosphere.

\begin{tabular}{cccccc}
\hline Samples & $\mathrm{T}_{5 \mathrm{wt} \%} /\left({ }^{\circ} \mathrm{C}\right)^{\mathrm{a}}$ & $\mathrm{T}_{\mathrm{d} 1} /\left(\% /{ }^{\circ} \mathrm{C}\right)^{\mathrm{b}}$ & $\mathrm{T}_{\mathrm{d} 2} /\left(\% /{ }^{\circ} \mathrm{C}\right)^{\mathrm{c}}$ & $\mathrm{T}_{\mathrm{d} 3} /\left(\% /{ }^{\circ} \mathrm{C}\right)^{\mathrm{d}}$ & $\mathrm{CR}_{550^{\circ} \mathrm{C}} /(\%)^{\mathrm{e}}$ \\
\hline LDPE & 418.25 & - & - & 477.18 & 0 \\
50L35WF & 288.73 & 308.31 & 356.16 & 476.86 & 14.67 \\
50L35WF-PA(H) & 286.74 & 292.40 & 327.89 & 479.60 & 19.36 \\
50L35WF-PA(N) & 280.28 & 289.71 & 334.61 & 476.81 & 22.54 \\
45L40WF-PA(N) & 277.04 & 296.81 & 338.34 & 475.69 & 25.80 \\
40L45WF-PA(N) & 268.63 & 288.13 & 326.08 & 473.43 & 22.67 \\
30L55WF-PA(N) & 262.49 & 278.97 & 316.63 & 474.85 & 29.32 \\
\hline
\end{tabular}

${ }^{\mathrm{a}} \mathrm{T}_{5 \mathrm{wt} \%}$ : the temperature at $5 \%$ weight loss; ${ }^{\mathrm{b}} \mathrm{T}_{\mathrm{d} 1}$ : the temperature at which the first peak of derivative weight loss; ${ }^{\mathrm{c}}$ $\mathrm{T}_{\mathrm{d} 2}$ : the temperature at which the second peak of derivative weight loss; ${ }^{\mathrm{d}} \mathrm{T}_{\mathrm{d} 3}$ : the temperature at which the third peak of derivative weight loss; ${ }^{\mathrm{e}} \mathrm{CR}_{550^{\circ}} \mathrm{C}$ : the char residues at $550^{\circ} \mathrm{C}$. 


\section{Mechanical analysis}

The results of tensile test of the LDPE composite are shown in Fig. 3 and Table 3. The tensile strength value of 50L35WF and 50L35WF-PA(N) were almost the same, 16.47 $\mathrm{MPa}$ and 16.87 $\mathrm{MPa}$, respectively. This behaviour might be ascribed to the composite contained the same content of WF additives. Notably, the tensile strength of LDPE/WF-PA(N) composites increased slightly from 16.87 $\mathrm{MPa}$ to $17.35 \mathrm{MPa}$ and $19.48 \mathrm{MPa}$ when the WF-PA(N) was added at $35 \mathrm{wt} \%, 40 \mathrm{wt} \%$ and $45 \mathrm{wt} \%$ respectively. This phenomenon was attributed to the addition of WF-PA(N) resulted in the better interfacial adhesion between the LDPE and WF-PA(N) which effectively in turn support the stress transfer between LDPE and WF-PA(N) (Ahmed et al., 2013; Catto et al., 2014; Taşdemır et al., 2009). It was found that the tensile strength of the 30L55WF-PA(N) was the highest one, indicating that there might be an optimum dispersion state between the LDPE matrix and WF-PA(N) fillers. As seen in Table 3 , the elongation at break analysis of LDPE/WF-PA(N) composites were 4.16\%, 2.93\%, 2.31\% and $1.16 \%$ for the WF-PA(N) was added at $35 \mathrm{wt} \%, 40 \mathrm{wt} \%$, $45 \mathrm{wt} \%$ and $55 \mathrm{wt} \%$, respectively. Obviously, the slightly decrement in elongation at break as increasing the content of WF-PA(N), resembling the less deformation gradient at break. It can be suggested that the presence of WF-PA(N) reduces the extent of elasticity and polymer chain mobility of the LDPE composites, resulting from the stiffening effect of wood flour. Therefore, the enhancement of rigidity (brittleness) was followed by increasing load of WF-PA(N) (Ahmed, 2015; La Mantia and Morreale, 2006).
To further examine the effectiveness of WF-PA(N) in mechanical properties, the impact strength of LDPE/WF$\mathrm{PA}(\mathrm{N})$ composites, by the measure of notched Izod impact strength, is shown in Fig. 4(a). The impact strength of the LDPE composites initially increases and then decreases with increasing the WF-PA(N) content. The highest impact strength of LDPE composites was achieved to $36.21 \mathrm{~J} / \mathrm{m}$, with the addition of $45 \%$ WF-PA(N) into the LDPE matrix. Above this concentration, the incorporation of WF-PA(N) dramatically decreases the impact strength of composites that may be related to a wood flour saturation in the LDPE matrix and a worse dispersion in certain regions (La Mantia et al., 2004; Morreale et al., 2008).

Heat distortion temperature analysis

To investigate the heat resistance and dimensional deformation behavior at high temperature, the heat distortion temperature (HDT) analysis of the composites is depicted in Fig. 4(b) and Table 3. The HDT value of 50L35WF (without PA content) was found to be about $86^{\circ} \mathrm{C}$. After blending with WF-PA(N), the HDT of LDPE/WF$\mathrm{PA}(\mathrm{N})$ composites further shifted to $102.6^{\circ} \mathrm{C}$ with the incorporation of $55 \%$ of WF-PA(N). The HDT value of composites was gradually increase with increasing the WF$\mathrm{PA}(\mathrm{N})$ content, in agreement with the trends observed for the tensile strength. In addition, the HDT value of 30L55WF-PA(N) was higher than that of 50L35WF-PA(N), and it is consistent with the results obtained by the TGA experiments. It is likely that the enhanced HDT of LDPA/WF-PA(N) composites arises from the fact that WF$\mathrm{PA}(\mathrm{N})$ flour has a capability to restrict the polymer chains, due to the higher filling degree it can grant. In our research,

Table 3. Physical properties of LDPE/WF-PA composites including tensile strength, elongation, impact strength, Heat distortion temperature (HDT), and UL94 horizontal burning (HB) test.

\begin{tabular}{cccccc}
\hline Samples & $\begin{array}{c}\text { Tensile strength } \\
(\mathrm{MPa})\end{array}$ & $\begin{array}{c}\text { Elongation } \\
(\%)\end{array}$ & $\begin{array}{c}\text { Impact strength } \\
(\mathrm{J} / \mathrm{m})\end{array}$ & $\begin{array}{c}\text { HDT } \\
\left({ }^{\circ} \mathrm{C}\right)\end{array}$ & $\begin{array}{c}\text { Burning rate } \\
(\mathrm{mm} / \mathrm{min})\end{array}$ \\
\hline 50L35WF & $16.47 \pm 0.71$ & $3.91 \pm 0.71$ & $37.30 \pm 3.50$ & $86.00 \pm 0.80$ & 43.19 \\
50L35WF-PA(N) & $16.87 \pm 1.43$ & $4.16 \pm 0.76$ & $33.31 \pm 3.87$ & $82.60 \pm 2.60$ & 32.85 \\
45L40WF-PA(N) & $17.35 \pm 0.67$ & $2.93 \pm 1.21$ & $35.74 \pm 0.93$ & $87.20 \pm 2.70$ & 26.47 \\
40L45WF-PA(N) & $19.48 \pm 0.43$ & $2.31 \pm 0.36$ & $36.21 \pm 3.64$ & $97.80 \pm 0.60$ & 25.01 \\
30L55WF-PA(N) & $19.30 \pm 0.45$ & $1.16 \pm 0.79$ & $25.75 \pm 2.31$ & $102.60 \pm 0.80$ & 16.06 \\
\hline
\end{tabular}
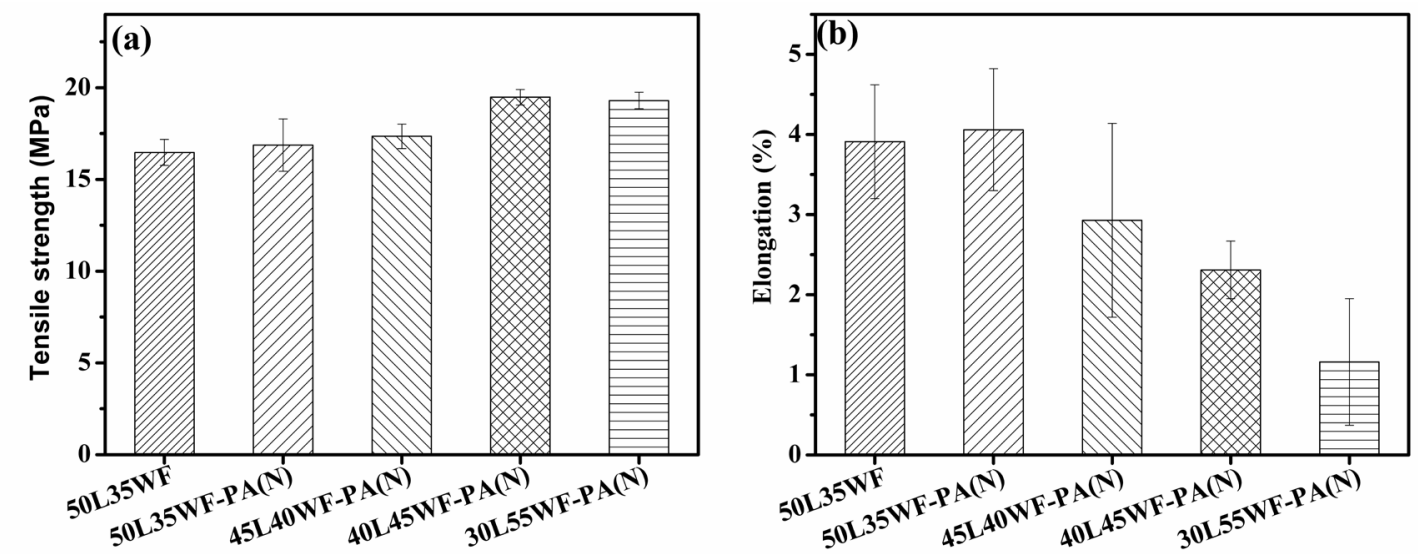

Fig. 3. (a) Tensile strength and (b) Elongation analysis of LDPE/WF and LDPE/WF-PA(N) composites 


\section{International Journal of Applied Science and Engineering}

Shih et al., International Journal of Applied Science and Engineering, 18(6), 2021266


Fig. 4 (a) Impact strength and (b) HDT analysis of LDPE/WF and LDPE/WF-PA(N) composites

the highest HDT and the flame retardant were achieved by the addition of $55 \%$ of WF-PA(N), enhancing the value of wood composites and the scope of practical applications.

Flame retardancy analysis

In the study, the horizontal burning (HB) test of UL-94 was employed to determine the HB flammability rating of the LDPE composites, and the results were manifested in Table 3 and Fig. 5. The flame spread rate of 30L55WF was recorded at $43.19 \mathrm{~mm} / \mathrm{min}$, respectively. We observed that the flame spread rate exhibited dramatically reduction as increasing the WF-PA(N) contents. Among all composites, the 30L55WF-PA $(\mathrm{N})$, containing 55\% WF-PA(N) in the
LDPE matrix, presented a flame spread rate of 16.06 $\mathrm{mm} / \mathrm{min}$. Generally, such phenomenon could be ascribed to the fire retardant fillers(WF-PA(N)) in polymer matrix (LDPE) that restrain composite combustion associated with char layer formation on the surface inhibiting internal layers from the external heating environment (Nicole et al., 2010; Umemura et al., 2014; Al-Majali et al., 2019). Therefore, it is clear that the addition of phytic acid modified wood (WF$\mathrm{PA}(\mathrm{N})$ ) not only can significantly improve in flame retardant properties, but help to reduce the carbon footprint of plastics through reusing wood flours to meet the environmental protection trends.


Fig. 5. (a) Burning rate analysis and $(\mathrm{b} \sim \mathrm{f})$ the burning process of LDPE/WF and LDPE/WF-PA(N) composites 


\section{CONCLUSION}

In this study, an eco-friendly flame-retardant LDPE/WFPA(N) composite, with phytic acid modified wood flour and the silane coupling agent treated diatomite, has been developed by the melt blending method. Accordingly, the TGA results indicate that char yield of the LDPE/WF-PA(N) composites can be enhanced via addition of WF-PA(N), which was in good agreement with the horizontal burning (HB) test, and meet the environmental protection trends. Furthermore, the composite containing $45 \%$ of WF-PA(N) exhibits the best tensile and impact strength, indicating the well compatibility between LDPE and WF-PA. Therefore, the eco-friendly flame-resistant formulation can be applied to interior decoration or as building materials in the future to meet the environment trends.

\section{REFERENCES}

Ahmed, K. 2015. Hybrid composites prepared from Industrial waste: Mechanical and swelling behavior. Journal of Advanced Research, 6, 225-232.

Ahmed, K., Nizami, S.S., Raza, Z.N., Mahmood, K. 2013. Effect of micro sized marble sludge on physical properties of natural rubber composites. Chemical Industry and Chemical Engineering Quarterly, 19, 281293.

Al-Majali, Y.A., Chirume, C.T., Marcum, E.P., Daramola, D.A., Kappagantula, K.S., Trembly, J.P. 2019. Coalfiller-based thermoplastic composites as construction materials: A new sustainable end-use application, ACS Sustainable Chemistry \& Engineering, 7, 16870-16878.

Arslan, F., Dilsiz, N. 2020. Flame resistant properties of LDPE/PLA blends containing halogen-free flame retardant. Journal of Applied Polymer Science, 137, 48960.

Brebu, M., Vasile, C. 2010. Thermal degradation of lignin a review. Cellulose Chemistry and Technology, 44, 353363.

Catto, A.L., Montagna, L.S., Rossini, K., Santana, R.M.C. 2014. Processing of post-consumer HDPE reinforced with wood flour: Effect of functionaliation methodology. AIP Conference Proceedings 1593, 487.

Chan-Hom, T., Yamsaengsung, W., Prapagdee, B., Markpin, T., Sombatsompop, N. 2017. Flame retardancy antifungal efficacies and physical-mechanical properties for wood/polymer composites containing zinc borate. Fire and Materials, 41, 675-687.

Gao, Y.Y., Deng, C., Du, Y.Y., Huang, S.C., Wang, Y.Z. 2019. A novel bio-based flame retardant for polypropylene from phytic acid. Polymer Degradation and Stability, 161, 298-308.

Geueke, B., Groh, K., Muncke, J. 2018. Food packaging in the circular economy: Overview of chemical safety aspects for commonly used materials. Journal of Cleaner Production, 193, 491-505.
Guiot, O., Tighzert, L., Coqueret, X. 1999. Electron beam crosslinking of extrusion-blown LDPE films: I. mechanical properties. European Polymer Journal, 35, 565-570.

Hörold, S. 1999. Phosphorus flame retardants in thermoset resins polymer degradation and stability, 64, 427-431.

Ibibikcan, E., Kaynak, C. 2014. Usability of three boron compounds for enhancement of flame retardancy in polyethylene-based cable insulation materials. Journal of Fire Sciences, 32, 99-120.

Kausar, A., Rafique, I., Anwar, Z., Muhammad, B. 2016. Recent developments in different types of flame retardants and effect on fire retardancy of epoxy composite. Polymer-Plastics Technology and Engineering, 55, 1512-1535.

Kim, H.S., Kim, S., Kim, H.J., Yang, H.S. 2006. Thermal properties of bio-flour-filled polyolefin composites with different compatibilizing agent type and content. Thermochimica Acta, 451, 181-188.

Kim, S. 2003. Flame retardancy and smoke suppression of magnesium hydroxide filled polyethylene. Journal of Polymer Science Part B Polymer Physical, 41, 936-944.

La Mantia, F., Dintcheva, N.T., Morreale, M., Vaca-Garcia, C. 2004. Green composites of organic materials and recycled post-consumer polyethylene polymer International, 53, 1888-1891.

La Mantia, F., Morreale, M. 2006. Mechanical properties of recycled poly-ethylene ecocomposites filled with natural organic fillers. Polymer Engineering and Science, 46, 1131-1139.

Lewin, M., Weil, E.D. 2001. Mechanisms and modes of action in flame retardancy of polymers. Fire Retardant Materials, 1, 31-68.

Lu, H., Wilkie, C.A. 2010. Study on intumescent flame retarded polystyrene composites with improved flame retardancy. Polymer Degradation and Stability, 95, 23882395.

Mordor Intelligence Pvt Ltd. 2020. Low-density polyethylene (LDPE) market-growth, trends, COVID-19 impact, and forecasts (2021 - 2026) Mordor intelligence press. Gachibowli Hyderabad. India. (accessed 09.11.2021).

Morreale, M., Scaffaro, R., Maio, A., La Mantia, F.P. 2008. Effect of adding wood flour to the physical properties of a biodegradable polymer. Composites Part A: Applied Science and Manufacturing, 39, 503-513.

Nicole, M., Stark, Robert H., White, Mueller, Scott A., Osswald, Tim A. 2010. Evaluation of various fire retardants for use in wood flour-polyethylene composites. Polymer Degradation and Stability 2010, 95, 1903-1910.

Poletto, M., Zattera, A.J., Forte, M.M., Santana, R.M. 2012. Thermal decomposition of wood: influence of wood components and cellulose crystallite size. Bioresource Technology, 109, 148-153.

Prasad, V.S., Pillai, C.K.S. 2000. Flame retardation of polyethylene: Effect of a phosphorus flame retardant having both hydrophobic and hydrophilic groups in the 


\section{International Journal of Applied Science and Engineering}

Shih et al., International Journal of Applied Science and Engineering, 18(6), 2021266

same molecule. Journal of Applied Polymer Science, 77, 2631-2640.

Saad, N., Esa, N.M., Ithnin, H., Shafie, N.H. 2011. Optimization of optimum condition for phytic acid extraction from rice bran. African Journal of Plant Science, 5, 168-176.

Shih, Y.F., Tsai, W.L., Kotharangannagari, V.K. 2020. Development of eco-friendly flame-retarded high density polyethylene composites. Key Engineering Materials, 847, 55-60.

Taşdemır, M., Biltekin, H., Caneba, G.T. 2009. Preparation and characterization of LDPE and PP-Wood fiber composites. Journal of Applied Polymer Science, 112, 3095-3102.

Tirri, T., Aubert, M., Pawelec, W., Holappa, A., Wilén, C.E. 2016. Structure-property studies on a new family of halogen free flame retardants based on sulfenamide and related structures. Polymers, 8, 360.

Umemura, T., Arao, Y., Nakamura, S., Tomita, Y., Tanaka, T. 2014. Synergy effects of wood flour and fire retardants in flammability of wood-plastic composites, Energy Procedia, 56, 48-56.
Wang, P.J., Liao, D.J., Hu, X.P., Pan, N., Li, W.X., Wang, D.Y., Yao, Y. 2019. Facile fabrication of biobased PNCcontaining nano-layered hybrid: preparation, growth mechanism and its efficient fire retardancy in epoxy. Polymer Degradation and Stability, 159, 153-162

Wang, Z., Liu, Y., Li, J. 2017. Regulating effects of nitrogenous bases on the char structure and flame retardancy of polypropylene/intumescent flame retardant composites. ACS Sustainable Chemistry \& Engineering, 5, 2375-2383.

Yang, H., Yan, R., Chen. H., Zheng, C., Lee, D.H., Liang, D.T. 2005. In-depth investigation of biomass pyrolysis based on three major components: hemicellulose, cellulose and lignin. Energy Fuels, 20, 388-393.

Zevenhoven, R., Karlsson, M., Hupa, M., Frankenhaeuser, M. 1997. Journal of the air \& waste management association, 47, 861-870. 